\title{
An investigation of categorical speech discrimination by rhesus monkeys*
}

\author{
PHILIP A. MORSE† and CHARLES T. SNOWDON \\ University of Wisconsin, Madison, Wisconsin 53706
}

\begin{abstract}
The categorical discrimination of synthetic human speech sounds by rhesus macaques was examined using the cardiac component of the orienting response. A within-category change which consisted of stimuli differing acoustically in the onset of F2 and F3 transitions, but which are identified by humans as belonging to the same phonetic category, were responded to differently from a no-change control condition. Stimuli which differed by the same amount in the onset of F2 and F3 transitions, but which human observers identify as belonging to separate phonetic categories, were differentiated to an even greater degree than the within-category stimuli. The results provide ambiguous data for an articulatory model of human speech perception and are interpreted instead in terms of a feature-detector model of auditory perception.
\end{abstract}

Recent research in human speech perception has suggested that humans perceive the sounds of human speech in a special mode which differs from that for other auditory signals (Liberman, Cooper, Shankweiler, \& Studdert-Kennedy, 1967; Liberman, 1970). Perception in the speech mode is characterized by the processing of speech sounds primarily in the dominant hemisphere (Studdert-Kennedy \& Shankweiler, 1970), by the presence of the lag effect (Porter, 1971), and by the phenomenon of categorical perception (Mattingly, Liberman, Syrdal, \& Halwes, 1971). In studies of categorical perception, the subject's discrimination of differences in synthetic speech stimuli is compared to his ability to identify the stimuli as belonging to different phonetic categories. Perception is said to be categorical if the subject is able to discriminate only two stimuli which he identifies as phonetically different and discriminates at chance two stimuli which differ by the same

\footnotetext{
*This study is Publication 13-044 of the Affiliate Scientist Program of the Wisconsin Regional Primate Research Center (U.S.P.H.S. Grant RR00167). Additional support came from NIH Biomedical Research funds from the University of Wisconsin Graduate School Research Committee and from the Waisman Mental Retardation Center (NICHD Grant 5-01-HD 03352). We would like to thank F. S. Cooper for his generosity in making the facilities at Haskins Laboratories available for generating the stimulus tapes and D. B. Pisoni for his helpful advice in the preparation of the stimuli and the final manuscript. Special recognition is due P. Lieberman. whose research and ideas about the evolution of speech prompted this study. We are grateful to $R$. W. Goy, Director of the Wisconsin Primate Center for making the animals and facilities available to us and to R. E. Bowman, J. W. Davenport, F. K. Graham, L. E. Ross, and C. Weisbard for the loan of equipment and for valuable technical advice. $W$. W. Hagquist, D. Mohr, and K. Schiltz also provided valuable technical assistance. R. E. Goldschmidt, R. Romero, and P. Swoboda assisted with the testing of subjects.

†Address reprint requests to: Philip A. Morse, Department of Psychology, University of Wisconsin, Madison, Wisconsin 53706.
}

acoustic amount but are assigned the same phonetic label. Evidence of between-category discrimination exceeding chance within-category discrimination has been obtained for the acoustic cues which signal phonetic differences in place of articulation (e.g., /b/, /d/, /g/: Mattingly et al, 1971; Pisoni, 1971, 1973), voicing (e.g., /d/, /t/: Liberman, Harris, Kinney, \& Lane, 1961), and in certain paradigms for the vowels /i/, /I/, / $\varepsilon /$ (Pisoni, 1971, 1973). In contrast, perception of nonspeech control stimuli, which contain the same acoustic difference in the second formant (F2) transition responsible for the differences in $/ \mathrm{b} /, / \mathrm{d} /, / \mathrm{g} /$, does not evidence better discrimination between categories than within categories. Instead, perception is described as continuous for these nonspeech stimuli, with discrimination generally better than chance throughout the F2 transition continuum (Mattingly et al, 1971). In sum, phonetic categorization severely limits the adult human's ability to discriminate withincategory differences in speech stimuli, whereas perception of nonspeech stimuli is continuous along an acoustic continuum, not categorical.

One current account of human speech perception posits that the abstraction of these phonetic categories from the acoustic signal is accomplished by a complex code which is primarily articulatory in nature (Liberman et al, 1967; Studdert-Kennedy, Liberman, Harris, \& Cooper, 1970). Some investigators interested in the acquisition of language have interpreted this theoretical position to imply that the infant's ability to employ phonetic categories in his perception of speech sounds would necessarily follow ontogentically his ability to produce these phonetic categories in his vocal repertoire (Gibson, 1969; Lenneberg, 1967).

However, recent studies in infant speech perception have indiated that the infant's perception of speech 
appears ontogenetically prior to his articulatory mastery of phonetic categories. Eimas, Siqueland, Juszcyk, and Vigorito (1971), using a nonnutritive sucking habituation-dishabituation paradigm, have demonstrated that discrimination of the voicing contrast /b/vs / $/$ / in English is categorical in 1- and 4-month-old infants. Eimas (1974) has replicated this finding with the $/ \mathrm{da} /-/ \mathrm{ta} /$ contrast in 2 - and 3-month-olds. Additional studies employing a nonnutritive sucking paradigm (Eimas, 1974, in press; Morse, 1972) have shown that infants respond to differences in the acoustic cues for the place of articulation (F2 and F3 transitions) in a markedly different manner than their responses to these same cues in a nonspeech context. Morse (1972) found that infants 40-54 days of age showed a different pattern of dishabituation to the F2 and F3 transitions in isolation when compared to these same cues in the speech syllables /ba/ and /ga/. Eimas (1974, in press) has reported that infants between 2 and 3 months of age exhibit categorical discrimination for stop consonants which vary in place of articulation $(/ d / v s / g /)$. Since data of infant speech production have indicated that these voicing and place of articulation contrasts do not appear in the infant's articulatory repertoire until 5 months to 2 years of age (Irwin, 1957; Port \& Preston, 1972), these infant speech perception studies do suggest that the adult phonetic categories are available to the infant well in advance of his productive use of these categories.

Although these infant findings might be construed as embarrassing to the theoretical account of adult speech perception offered above, a modification that is consistent with both an articulatory theory and the infant data has been proposed. It might be that "knowledge" of adult phonetic categories is a phylogenetic development within the perceptual system rather than ontogenetically dependent upon articulatory development (Eimas, in press; Lieberman 1973; Mattingly, 1972; Morse, 1971). Studies of the evolution of the human vocal tract (Lieberman, 1973; Lieberman, Crelin, \& Klatt, 1972; Lieberman, Klatt, \& Wilson, 1969) have demonstrated that the shape of the supralaryngeal vocal tracts of the thesus monkey, chimpanzee, and Neanderthal man precludes the production of the full range of human speech sounds. Although these analyses focus primarily on the vowel repertoires of these organisms, they also indicate that the production of the full range of stop consonants which vary in place of articulation (e.g., /b/, /d/, $/ g /$ ) would also be precluded in these species. If the articulatory apparatus of man is species-specific, then it is reasonable to suggest that man may also have evolved a unique perceptual system for decoding species-specific vocalizations (Lieberman, 1973; Mattingly, 1972). This might be similar to the match between auditory detector mechanisms and vocal production systems in the bullfrog (Frishkopf,
Capranica, \& Goldstein, 1968).

The present study was designed to pursue this phylogenetic hypothesis. Accordingly, if the evolution of perceptual phonetic categories accompanied the evolution of articulatory structures for the production of these categories, then perceptual phonetic categories should be absent in a species which has not also evolved articulatory structures for producing phonetic categories. Specifically, nonhuman primates (e.g., rhesus monkey) should not evidence categorical discrimination of speech sounds, since they are unable to produce the phonetic categories of speech.

Weisbard and Graham (1971) have suggested a feasible technique for investigating speech discrimination in nonhuman primates. They demonstrated that an auditory stimuius of moderate intensity and rise time presented to stump-tailed macaques produced a heart-rate orienting response (deceleration). With repeated presentations of the same stimulus, the neart-rate orienting response (OR) habituated. The subsequent presentation of a novel stimulus (frequency change) resulted in the reliable dishabituation (recovery) of the subject's OR. The present experiment employed a modification of the Weisbard and Graham paradigm to investigate the categorical discrimination of the stop consonants $/ b /$, $/ \mathrm{d} /$, and $/ \mathrm{g} /$ in rhesus macaques.

\section{METHOD}

\section{Subjects and Apparatus}

The subjects were eight (seven male, one female) laboratoryraised thesus monkeys (Macaca mulatia) with a mean age of 3.87 years (range: $3-5$ years). For the duration of the experiment (6-8 days), each subject lived in a Lehigh Valley primate chair mounted on a movable cart. All animals were tested inside a Lehigh Valley sound-attenuated cubicle which, in turn, was mounted inside two larger sound-attenuated chambers.

The speech stimuli were presented via a Sony 770-4 tape deck and a Dynaco Mark II amplifier through a speaker mounted approximately $60 \mathrm{~cm}$ in front of the subject. An audio-threshold relay (Scientific Prototype) detected stimulus artifact pulses from one channel of the stimulus tape and recorded them on one channel of a Grass 7 polygraph and on one channel of a Magnecord No. 1028 tape recorder. Heart rate was recorded from 28-ga stainless steel wire threaded through the animal's skin and tied to form small loops. These were connected to the electrode leads of the polygraph by mini-banana jack connectors. The active electrodes were attached over the upper right and lower left rib cages with the ground electrode located over the upper left rib cage. The subject's EKG signal was displayed on one polygraph channel and was fed simultaneously into a cardiotachograph (permitting the display of the heart rate) and into a Schmitt-trigger pulser which produced a 1-msec square wave for each cardiac $R$ wave as input to the second channel of the Magnacord tape recorder.

\section{Stimulus Materials}

All stimuli employed in the present experiment were three formant $\mathrm{CV}$ patterns synthesized on the parallel-resonance synthesizer at Haskins Laboratories. They consisted of slightly modified versions of stimuli previously used in studies of adult human speech perception by Pisoni $(1971,1973)$. The specific stimuli selected from Pisoni's /bae/-/dae/-/gae/ continuum consisted of two / bae/ stimuli (Nos. 1 and 3), two /dae/ stimuli 
Table 1

Starting Frequencies, Steady State Frequencies, and Frequency Changes of the Second and Third Formant Transitions of the Five Experimental Stimuli

\begin{tabular}{|c|c|c|c|c|c|c|c|}
\hline & & \multicolumn{3}{|c|}{$\mathrm{F} 2$} & \multicolumn{3}{|c|}{ F 3} \\
\hline \multicolumn{2}{|c|}{ Stimuli } & Start & Steady State & Change & Start & Steady State & Change \\
\hline bae & $\begin{array}{l}1 \\
3\end{array}$ & $\begin{array}{l}1232 \\
1386\end{array}$ & $\begin{array}{l}1620 \\
1620\end{array}$ & $\begin{array}{l}+388 \\
+234\end{array}$ & $\begin{array}{l}2180 \\
2525\end{array}$ & $\begin{array}{l}2862 \\
2862\end{array}$ & $\begin{array}{l}+682 \\
+337\end{array}$ \\
\hline dae & $\begin{array}{l}5 \\
7\end{array}$ & $\begin{array}{l}1541 \\
1695\end{array}$ & $\begin{array}{l}1620 \\
1620\end{array}$ & $\begin{array}{r}+79 \\
-75\end{array}$ & $\begin{array}{l}2862 \\
3195\end{array}$ & $\begin{array}{l}2862 \\
2862\end{array}$ & $\begin{array}{r}0 \\
-333\end{array}$ \\
\hline gae & 13 & 2156 & 1620 & -536 & 2180 & 2862 & +682 \\
\hline
\end{tabular}

Note-The stimulus numbers (e.g., 1, 3) refer to the stimuli employed by Pisoni (1971, 1973).

(Nos. 5 and 7), and a /gae/ stimulus (No. 13). Each CV syllable was $500 \mathrm{msec}$ in duration, possessed a fundamental frequency of $120 \mathrm{~Hz}$ and a voice-onset-time value of $-20 \mathrm{msec}$. During the first $50 \mathrm{msec}$ of each stimulus, the first, second, and third formants moved to their steady-state levels of $743,1,620$, and $2,862 \mathrm{~Hz}$, respectively. The initial level of the first formant (F1) was set at $150 \mathrm{~Hz}$. The starting frequencies for the second formant (F2) and third formant (F3) of each stimulus are presented in Table 1. The onset frequencies for the $F 2$ and $F 3$ transitions differed by virtually equivalent amounts (ca. 154 and $338 \mathrm{~Hz}$, respectively) for Stimuli 1 vs 3,3 vs 5 , and 5 vs 7 . The formant bandwidths were 60,90 , and $120 \mathrm{~Hz}$ for $\mathrm{F} 1, \mathrm{~F} 2$, and $\mathrm{F} 3$, respectively. Both the amplitude level and envelope were held constant across all stimuli. These modified stimuli differed slightly from Pisoni's original set in duration $(300 \mathrm{msec})$, voice onset time $(-40 \mathrm{msec})$ and transition duration (40 msec). Previous discrimination functions gathered by Pisoni using an AX paradigm indicated that adult human subjects' discrimination of stimulus contrasts No. 1 vs No. 3 and No. 5 vs No. 7 (within categories) was basically at chance (approximately $50 \%$ correct), whereas the discrimination of stimulus contrast No. 3 vs No. 5 (between categories) was approximately $85 \%$ correct (Pisoni, 1973, Fig. 1).

Six stimulus tapes were prepared using these stimuli. Forty $\mathrm{CV}$ syllables were recorded on each tape with an interstimulus interval of $1 \mathrm{sec}$. Two tapes served as control tapes and contained a series of either 40 /bae/ stimuli (No. 3) or 40 /dae/ stimuli (No. 5). The four remaining tapes consisted of 20 syllables of one stimulus followed by 20 syllables of a second (change) stimulus. For two tapes, the stimulus shift was within a category, either within /bae/ (No. 3 to No. 1) or within /dae/ (No. 5 to No. 7). The final two tapes contained between-category changes from /dae/ to /bae/ (No. 5 to No. 3) and between /bae/ and /gae/ (No. 3 to No. 13). All stimulus sequences were recorded on one audio channel of the tape with a brief $2-\mathrm{KHz}$ tone artifact recorded on the second channel synchronous with the onset of the first syllable and with the onset of the 21 st stimulus (the first "change" stimulus). The tone artifacts were fed directly and solely into the audio relay and were inaudible to the $S$ during the experiment. Since all tape sequences were generated in their entirety using the Haskins' PCM (pulse-code modification) system, the recording of the sequences did not require any splicing or dubbing. All stimuli were delivered at approximately $72 \mathrm{~dB}(\mathrm{~A}, \mathrm{C}$, and $20-\mathrm{KHz}$ scales) against a $51-\mathrm{dB}$ background noise level. Sound-level readings were registered on a General Radio 1551-C sound-level meter placed at the site of the animal's head.

\section{Procedure}

Following the surgical attachment of the electrode loops (sewn subcutaneously under conditions of light anaesthesia), each animal was adapted in the primate chair to the experimental apparatus for 2 days. During the adaptation sessions, the subject was placed in the test chamber, the EKG electrodes were attached, EKG and heart rate were monitored for 6-10 $\mathrm{min}$, but no auditory stimuli were presented. After the adaptation days, the subject was presented with a different stimulus condition on each of the following 4-6 days.

During each experimental session, the animal was placed in the test chamber, the EKG electrodes attached, and the chamber sealed. Once visual monitoring of the monkey (through a peephole in the chamber) indicated that it was calm and alert (generally 1-5 min after placement in the chamber), both tape machines were started. A period of 20-30 sec of silence preceded the onset of the stimulus sequence on the audio tape. From onset of the audio tape through the termination of the stimulus sequence, the subject was rated by an observer for body movements, state changes, and behavioral orientation to both stimulus onset (Syllable 1) and stimulus change (Syllable 21). Following each session but prior to examination of the polygraph record, the observer decided whether the monkey's activity level and state were acceptable. Excessive movements and/or drowsiness were the sole grounds for rejection of a session.

Each subject was tested until it completed four or more experimental conditions that were rated as acceptable. Only subjects who successfully completed at least one control, one within-category, the $/ \mathrm{dae} /-/ \mathrm{bae} /$, and the $/ \mathrm{bae} /-/ \mathrm{gae} /$ condition were included in the study. An additional 14 animals were tested, which yielded some rater-acceptable sessions, but which failed to meet this minimum criterion for inclusion in the study. Six of the eight accepted subjects yielded data for the /bae/-/gae/ condition (B-G), the /dae/-/bae/ between-category condition (B), and either the /dae/ or /bae/ control (C) and within-category (W) shifts. The remaining two animals successfully completed additional $\mathrm{C}$ and $\mathrm{W}$ shift sessions. For purposes of analysis, instances of successful completion of more than one $\mathrm{C}$ or $\mathrm{W}$ shift within these two animals (e.g., /dae/-C and /bae/-C) were averaged to yield the animal's score for that condition (e.g., C). In sum, this procedure yielded data for each of the eight acceptable subjects in four experimental conditions: control (C), within-category (W), between-category (B), and $/ \mathrm{bae} /-/ \mathrm{gae} /(\mathrm{B}-\mathrm{G})$. The order of presentation of conditions was randomized over subjects, with no animals receiving the same test order.

\section{Heart-Rate Data Analysis}

A Laboratory Instrument Computer (LINC) calculated the time between successive cardiac $R$ waves to the nearest millisecond for $2 \mathrm{sec}$ preceding and $22 \mathrm{sec}$ following the onset of each 20 stimulus block (i.e., at Syllables 1 and 21). The LINC computer, in turn, converted these data to average heart rate $(H R)$ in beats per minute over seconds. Difference scores in HR change between the average for the two prestimulus seconds and each of the 22 poststimulus seconds were calculated for the onset and change syllables. These data were used in subsequent analyses of variance carried out by a Univac 1108 computer.

\section{RESULTS}

Analyses of variance of the second-by-second changes in heart rate from the prestimulus (Svllable 1 
or Syllable 21) level were performed on difference scores computed over the first $15 \mathrm{sec}$ following stimulus onset or stimulus change. Since Graham and Jackson (1970) have shown that approximately the first $10 \mathrm{sec}$ yield the most reliable period of cardiac orienting behavior in adult and infant humans and Weisbard and Graham (1971) have observed that orienting activity in stump-tailed monkeys occurs within $10-15 \mathrm{sec}$, the first half $(15 \mathrm{sec})$ of the response period rather than the entire period $(30 \mathrm{sec})$ was selected for analysis. In addition, the first $22 \mathrm{sec}$ (the maximum time period analyzable given the constraints of available computing facilities) were also subjected to analyses of variance, which produced substantially the same results as those obtained for $15 \mathrm{sec}$.

\section{Onset Data}

Since an analysis of variance of the mean heart-rate levels prior to stimulus onset revealed no reliable differences between the four conditions $(p>.10)$, all analyses of the onset data were performed on unadjusted difference scores.

The heart-rate difference scores to the initial stimulus (Syllable 1) in each 40-stimulus sequence were subjected to an analysis of variance with repeated measures over seconds (15) for the four experimental conditions (C, B-G, W, B). No reliable effects were observed due to conditions, seconds, or their interaction $(\mathrm{p}>.05$, all $\mathrm{Fs}<1)$. A subsequent analysis of variance performed on these difference scores for trends over seconds in selected orthogonal contrasts (C vs B-G, W, B; B-G vs W, B; W vs B) also revealed no reliable effects due to the linear, quadratic, or cubic trends ( $p s>.05$ ) in any of the contrasts. In addition, the linear, quadratic, and cubic trends for the onset response (taken over all conditions) did not approach significance. These findings indicate that no cardiac $O R$ was observed to stimulus onset when the entire four sessions were considered together. However, an OR might have occurred during the initial days of testing and subsequently habituated with repeated test sessions. The results of an analysis of variance performed on days (4) by seconds (15) in which trends on days and on seconds were examined revealed a quadratic trend for days by quadratic trend for seconds effect $(F=7.17$, df $=1,7, \mathrm{p}=.03$ ). As Fig. 1 suggests, this trend is due to the lack of any heart-rate response on Day 1 , followed by a large OR to the onset on Day 2, which subsequently habituated on Days 3 and 4 . Partial support for this interpretation of these changes in the OR over days can be found in the behavioral indices of orienting (e.g., eye-opening, ears back, headorienting) noted by the rater at stimulus onset. On Days 1,2 , and $3,100 \%$ of the sessions contained evidence of behavioral orienting to stimulus onset,

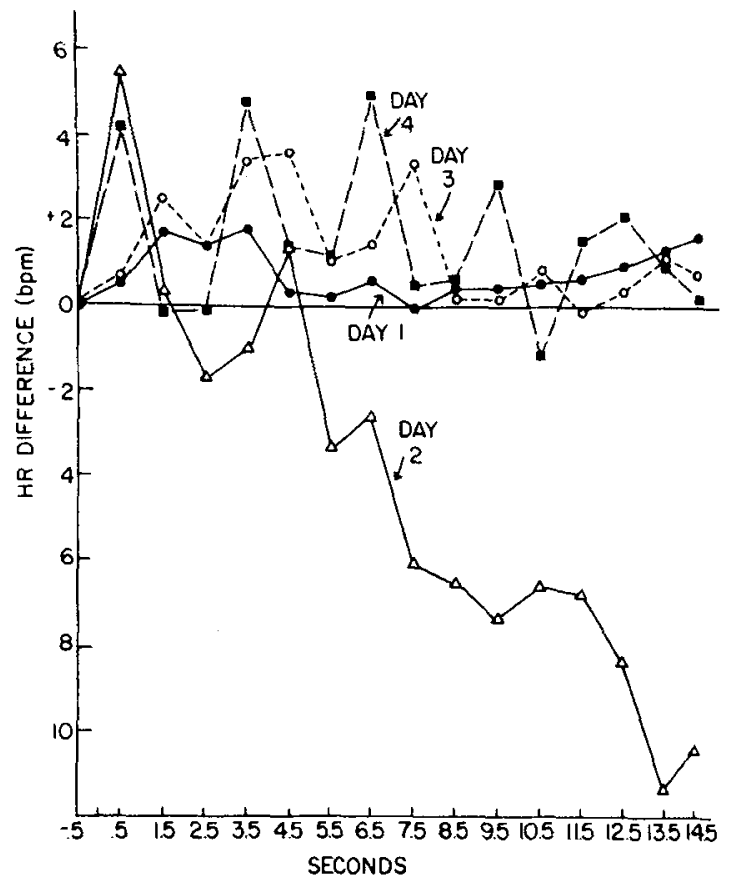

Fig. 1. Heart-rate difference scores to stimulus onset by days of presentation.

whereas subjects demonstrated behavioral ORs on only $62.5 \%$ of the sessions on Day 4 .

\section{Change Data}

No differences were observed between /bae/ vs /dae/ within conditions or in the /bae/ vs /dae/ control conditions. Consequently, the two within and the two control conditions were pooled, respectively, for subsequent analyses. The heart-rate difference scores for the response to the first change stimulus (Syllable 21) were subjected to a conditions (C, B-G, $\mathrm{B}, \mathrm{W}) \mathrm{x}$ seconds (15) analysis of variance. Since both the conditions effect $(\mathrm{F}=3.91$, $\mathrm{df}=3,21, \mathrm{p}<.05)$ and the Conditions by Seconds interaction $(F=2.05$, df $=42,294, p<.01$ ) proved to be reliable, subsequent analyses of variance were performed in which linear, quadratic, and cubic trends over seconds were examined for selected orthogonal contrasts. In one set of contrasts (C vs B-G, W, B; $\mathrm{B}-\mathrm{G}$ vs $\mathrm{W}, \mathrm{B}$; W vs B), the C condition was found to differ from the other three conditions both in overall level of the heart-rate response $(F=5.56, \mathrm{df}=1,7, \mathrm{p}$ $=.0505)$ and in the quadratic trend over seconds $(\mathrm{F}$ $=10.17, \mathrm{df}=1,7, \mathrm{p}=.02$ ). These results may be interpreted as suggesting the discrimination of both the between- and within-category changes (as well as the two-category B-G change) in rhesus monkeys. As can be seen in Fig. 2, these effects are due to the accelerated heart-rate response in the control condition, which differs from the decelerative or 


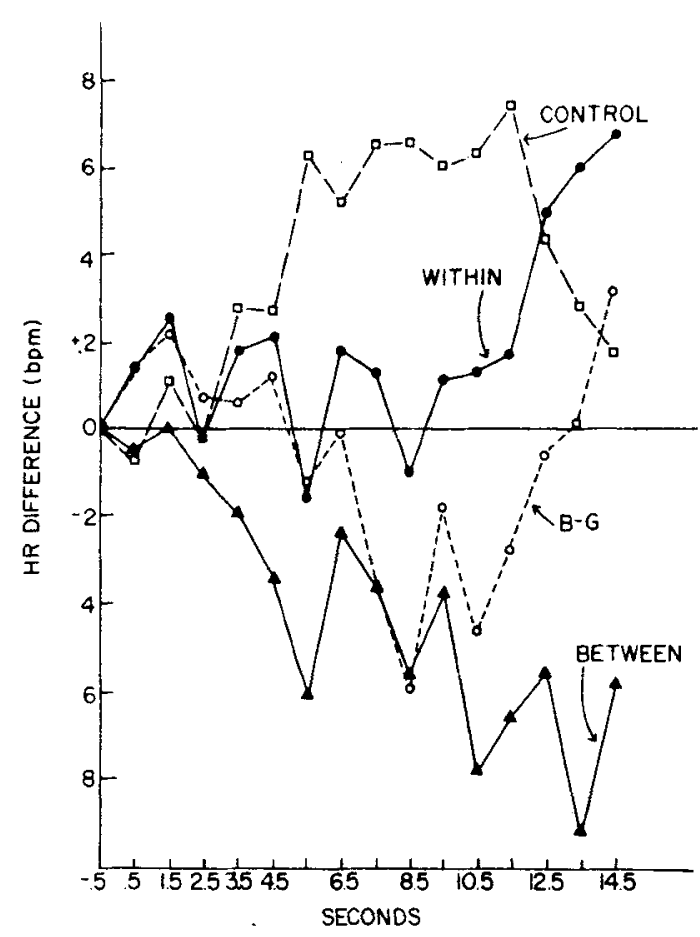

Fig. 2. Heart-rate difference scores to stimulus change as a function of change condition.

nonaccelerative responses of Conditions B-G, B, and W.

Although subjects demonstrated reliable differences in the three experimental conditions when compared together with the control, as can be seen in Fig. 2, the pattern and level of the heart-rate change was not equivalent for Conditions W, B-G, and B. Additional orthogonal contrasts revealed a significant cubic trend over seconds for Conditions B-G vs W and $\mathrm{B}(\mathrm{F}=10.02, \mathrm{df}=1.7, \mathrm{p}=.02)$ and a marginal difference in the overall level of responding for the between-category vs within-category contrast $(\mathrm{F}=$ 4.32, $\mathrm{df}=1,7, \mathrm{p}=.08$ ). Other than the reliable overall cubic trend over seconds for all conditions combined $(\mathrm{F}=10.53$, df $=1,7, \mathrm{p}=.02)$, no other significant effects were observed for this set of orthogonal contrasts.

Additional contrasts established that the withincategory condition differed reliably from the control condition in the quadratic trend over seconds $(\mathrm{F}=$ $9.29, \mathrm{df}=1,7, \mathrm{p}=.02$ ) and that the overall level of the within-category change was significantly different from that of Conditions B and B-G when considered together $(F=6.74$, df $=1,7, p=.04)$. Finally, Conditions B-G and B were found to differ in their cubic trends over seconds $(F=7.80$, df $=1,7, p=$ $.03)$.

Analyses of variance for trends in the difference scores over days revealed no evidence of any main effect or linear, quadratic, or cubic trends for this variable ( $p s>.10)$. However, an analysis of the mean heart-rate levels prior to the change stimulus suggested a possible, though nonsignificant, difference in initial level between the four conditions $(F=2.72$, df $=3,21, p<.10)$. A subsequent analysis of variance for orthogonal contrasts ( $C$ vs B-G, B, W; B-G vs B, W; B vs W) yielded a significant difference in prestimulus level between the within- and between-category conditions $(F=25.79$, $\mathrm{df}=1,7, \mathrm{p}<.005)$. Consequently, the change data were reanalyzed with difference scores adjusted for their regression on prestimulus level (regression coefficient $=-1.21$ ). The major effects reported for the unadjusted scores were replicated in the adjusted score analyses, with the following exceptions. The previously marginally reliable $W$ vs $B$ condition difference became reliable when the adjusted scores were used $(\mathrm{F}=10.02, \mathrm{df}=1,7, \mathrm{p}=.02)$, and the overall level difference between Conditions $\mathrm{W}$ and $\mathrm{C}$ was also significant $(\mathrm{F}=11.28, \mathrm{df}=1,7, \mathrm{p}=.02)$.

\section{DISCUSSION}

\section{Attention to Speech}

A number of factors may have contributed to the limited evidence of cardiac orienting in the onset data of the present experiment. First, in most of the sessions, marked behavioral orienting (head rotation, eye opening, or ear movements) was observed to the transient produced by the tape recorder switch in turning on of the stimulus tape (20-30 sec prior to the onset of the stimulus sequence). It is possible that this initial orienting may have reduced the animal's subsequent $O R$ to stimulus onset. A second possibility is that cardiac ORs are more difficult to obtain in rhesus monkeys than in stump-tailed monkeys (Weisbard \& Graham, 1971). Although Weisbard \& Graham observed cardiac deceleration to stimulus onset in stump-tailed monkeys, Bagshaw and Benzies (1968) found that the rhesus monkey evidenced cardiac acceleration to stimulus onset. However, evidence from the present study of an onset OR on Day 2 and the responses to the change stimuli suggest that rhesus monkeys are quite capable of demonstrating cardiac deceleration to a novel stimulus. Furthermore, as Weisbard and Graham observed, the intensity levels and rise-times employed in the Bagshaw and Benzies study were more likely to elicit a defense response (heart-rate acceleration) than an OR, whereas the moderate intensity levels and slow rise-times in the Weisbard and Graham study yiclded evidence of cardiac orienting. In the present study, although the intensity levels were moderate, the rise-times $(50 \mathrm{msec})$ were relatively rapid and may have served to attenuate the animal's initial OR. With repeated exposure to the testing situation, these rapid rise-times may have become less threatening and more 
familiar to the subject. The OR on Day 2 to initial onset and perhaps its habituation on Days 3 and 4 coupled with the consistent OR to the change stimuli (preceded by 20 other stimuli with fast rise-times) provide some support for this explanation.

\section{Discrimination of Speech}

According to the theoretical account of human speech perception offered above, perceptual phonetic categories are primarily a consequence of evolved articulatory categories and capabilities in the human speaker. Since the rhesus monkey does not possess a vocal tract capable of the range of human speech sounds, we predicted in the present study that within-category discrimination would not be constrained by phonetic categories and, furthermore, that the discrimination of a given acoustic difference, whether within- or between-categories, would be equivalent. The results revealed that the rhesus monkey's within-category discrimination did differ reliably from the control condition, but yet was significantly inferior to that of the between category condition. At first glance, these two major findings would appear to contradict each other. On the one hand, the within-category/control difference is consistent with the theoretical account of speech perception described above, whereas the difference between the within-category and between-category conditions would seem to argue against this account. In the discussion which follows, these two major findings will be examined as they relate to this theoretical account of human speech perception.

The finding that the within-category condition differs reliably from the control condition may be interpreted as evidence of within-category discrimination in the rhesus monkey. A number of factors suggest that this interpretation of the data may be appropriate, though additional studies with the heartrate orienting response in man and monkey may be necessary before we can be certain of this interpretation. To begin with, the significant difference between these two conditions is not a result of a cardiac deceleration to the within-category change, but due instead to a cardiac acceleration in the control condition. Is this acceleration in the control condition a replicable phenomenon, and, if so, what underlying processes may be responsible for this acceleration? Although no attempts have been made to determine the repeatability in monkeys of the control condition's accelerative response, similar within-subject experiments of categorical discrimination currently in progress in our laboratory with adult humans indicate that under some conditions an accelerative response is also observed in the control condition. One possible theoretical explanation for this acceleration may be that it reflects considerable habituation of the OR to the original stimulus (cf. Graham \& Clifton, 1966). If this interpretation is correct, one might expect that cardiac acceleration would be related to the number or rate of stimulus presentation (i.e., amount of habituation allowed) rather than the occurrence of a "control shift." A subsequent study, in which subjects are run with either fewer or more than 20 stimuli prior to the point of shift, would provide important data on this interpretation.

Additional factors further suggest that the reliable difference observed between the control and within-category conditions does reflect discrimination in the rhesus monkey. First, the only difference between the stimulus tapes for the two conditions is the presence of a stimulus change after the first 20 stimuli on the within-category tape. In short, cardiac behavior similar to the control condition is what one would expect if subjects were unable to discriminate a within-category stimulus change. The within-category condition failed to show the same response pattern as the control condition, even though heart-rate deceleration to the change was not observed. Secondly, evidence of within-category discrimination in monkeys has recently been observed by Sinnott (1974). Sinnott found that latency measures in an operant conditioning paradigm revealed that monkeys were capable of discriminating sounds within the $/ \mathrm{ba} /$ and /da/ categories.

Although the data in the present study suggest that rhesus monkeys can discriminate within the categories of $/ \mathrm{bae} /$ and $/ \mathrm{dae} /$, the relationship of these findings to the human adult literature is far from clear. In his studies of adult perception, Pisoni (1973) observed, using an AX paradigm, that discrimination of the within-category contrasts used in the present study was within one or two percentage points of chance (Pisoni, personal communication). However, no statistical tests were imposed on these data to determine if they differed reliably from chance. Pisoni's (1971) experiments have further demonstrated that for vowels, in contrast to stop consonants, the particular discrimination paradigm employed can greatly influence the degree of within-category discrimination observed. Consequently, a comparison of heart-rate data on within-category discrimination in monkeys with the data from AX or ABX paradigms with human subjects would be clearly unjustified. However, a discrimination paradigm employing a similar repeated stimulus procedure has shown that 2 and 3-month-old infants failed to discriminate within-category differences in $/ \mathrm{dae} /$, whereas comparable between-category differences (/dae/ vs /gae/) were discriminated (Eimas, 1974). Until similar heart-rate response data from humans are available, the strongest statement that can be made regarding species differences in man and monkey is that, while several studies employing a number of different paradigms have found that within-category discrimination for stop consonants is not easily 
evidenced in human adults (e.g., Pisoni, 1971), the rhesus monkey appears to demonstrate withincategory discrimination in a paradigm in which he is a relatively passive participant.

The second major finding of the present study is the within-/between-category difference in discrimination. The interpretation that the increased deceleration of the between-category condition reflects greater discrimination between categories than within them finds support in human adult discrimination data in which the magnitude of heart-rate deceleration has been found to be positively related to the magnitude of pitch discriminability (Cicerelli, reported in Graham, 1973). Similar findings have been reported for the amount of acoustic change and the magnitude of the galvanic skin response (Cicerelli, reported in Graham, 1973; Corman, 1967; Geer, 1969; Williams, 1963).

Certainly one possible interpretation of this evidence of superior between-category discrimination is that phonetic categories are not necessarily a consequence of evolved articulatory capabilities as posited by the theoretical account of speech perception offered above. On the other hand, several factors suggest that an outright rejection of this theoretical account based on these findings may be premature. For one, it should be remembered that the within-/between-category difference became significant only when adjusted heart-rate scores are employed. Secondly, recent interpretations of human speech adaptation data in terms of feature-detector mechanisms (Aides, 1973; Cooper, 1973; Eimas, Cooper, \& Corbit, 1973; Eimas \& Corbit, 1973; Stevens, 1973) suggest that perhaps nonphonetic feature detectors may play an important role in the within-/between-category difference observed in rhesus monkeys. For example, Aides (1973) has shown that in human adults a reliable adaptation effect can be observed to speech and nonspeech (chirps and tweets) stimuli which differ in their F2 and F3 transitions along the /bae-dae-gae/ continuum. Stevens (1973) has proposed that three types of feature detector mechanisms might be sufficient to account for the perception of $/ b /, / d /$, and $/ g /:$ (1) a detector responding to an upward shift in the frequency spectrum $(/ \mathrm{bae} /)$, (2) a detector responding to a downward shift in the frequency spectrum (/dae/), and (3) a detector responsive to both an upward (F3) and a downward (F2) shift in the frequency spectrum (/gae/).

According to such a model, discrimination might be expected to be relatively poor if two stimuli share the same acoustic features (e.g., an upward shift in the frequency spectrum), better if they have different acoustic features, and perhaps intermediate if they contain some shared and some different features. An examination of the stimuli employed in the present study (cf. Table 1) suggests a reasonably good fit between the results of the present study and the feature-detector model proposed by Stevens. The two /bae/ stimuli employed both contained an upward shift in the frequency spectrum. The fit for the two /dae/ stimuli is not as easy. If the assumption is made that the flat F3 transition in Stimulus 5 overrides the slight rise in F2 to yield a directional shift in the frequency spectrum more similar to the downward shift in the second /dae/ (No. 7) than to the upward shift in /bae/ (No. 3), then one might expect the within-category /dae/ condition to elicit less discrimination than the /dae/-/bae/ change. Finally, based on the stimulus values for No. 3 vs No. 13, the /bae/-/gae/ condition, as expected, yields an intermediate level of discrimination when compared to the within- and between-category changes. In the absence of more information about the monkey's relative weightings of $F 2$ and $F 3$ frequency changes, this interpretation of the between- vs within-category differences must remain very speculative. However, examination of rhesus monkey calls (Rowell \& Hinde, 1962; Figs. 4, 5, 13) reveals instances of rapid shifts in the frequency spectrum, for which feature analyzers similar to those proposed by Stevens might well be important in rhesus communication. Clearly, a replication of the present experiment with two rather than three formant patterns would be extremely valuable in assessing the usefulness of this feature-detector explanation of monkey speech perception.

In summary, the results of the present study demonstrate that the heart-rate OR habituation/ dishabituation paradigm is a viable technique for the study of speech perception in rhesus monkeys. Employing this paradigm, subjects were found to discriminate a between-category change of a given acoustic difference in the F2 and F3 transitions better than a within-category change of the same acoustic difference. Finally, within-category performance also differed reliably from that in the control condition. When considered together, these findings do not permit an easy answer to the question of the evolved articulatory basis of human speech perception. Instead, they suggest that additional studies in man and monkey using the cardiac orienting response in assessing the discrimination of F2 (and F3) transition cues in speech and nonspeech contexts are necessary to elucidate the complex relationship between phonetic vs nonphonetic perception and articulatory capabilities in primates.

\section{REFERENCES}

Aides, A. Some effects of adaptation on speech perception. M.T.I. Research Laboratory of Electronics Quarterly Progress Report, 1973, 111, 121-129.

Bagshaw, M., \& Benzies, S. Multiple measures of the orienting reaction and their dissociation after amygdalectomy in monkeys. Experimental Neurology, 1968, 20, 175-187. 
CoOper, W. Adaptation of linguistic feature detectors for place of articulation. Unpublished Master's thesis, Brown University, 1973.

Corman, C. Stimulus generalization of habituation of the galvanic skin response. Journal of Experimental Psychology, 1967, 74, 236-240.

EImas, P. Developmental studies of speech perception. In L. Cohen and $P$. Salapatek (Eds.), Infant perception. New York: Academic Press, in press. Eimas, P., Cooper, W., \& Corbit, J. Some properties of linguistic feature detectors. Perception \& Psychophysics, 1973, 13, 247-252.

Eimas, P. D. Auditory and linguistic processing of cues for place of articulation by infants. Perception \& Psychophysics, 1974, 16, 539-541.

Eimas, P., \& Corbit, J. Selective adaptation of linguistic feature detectors. Cognitive Psychology, 1973, 4, 99-109.

Eimas, P., Siqueland, E., Jusczyk, P., \& Vigorito, J. Speech perception in infants. Science, 1971, 171, 303-306.

Frishropf, L., CAPRANica, R., \& Goldstein, M. Neural coding in the bullfrog's auditory system: A teleological approach. Proceedings of the IEEE, 1968, 56, 969-980.

GEER, J. Generalization of inhibition in the orienting response. Psychophysiology, 1969, 6, 197-201.

GiBson, E. Principles of perceptual learning and development. New York: Appleton-Century-Crofts, 1969.

GraHAM, F. Habituation and dishabituation of responses innervated by the autonomic nervous system. In $\mathrm{H}$. Peeke and M. Herz (Eds.), Habituation: Behavioral studies and physiological substrates. New York: Academic Press, 1973. Pp. 163-218.

Graham, F. \& C Cifton, R. Heart-rate change as a component of the orienting response. Psychological Bulletin, 1966, 65, 305-320.

Graham, F., \& JaCkson, J. Arousal systems and infant heart rate responses. In L. P. Lipsitt and H. Reese (Eds.), Advances in child behavior. Vol. V. New York: Academic Press, 1970. Pp. 54-117.

IRwIN, O. Phonetical description of speech development in childhood. In L. Kaiser (Ed.), Manual of phonetics. Amsterdam: North-Holland, 1957. Pp. 403-425.

LENNEBERG, E. Biological foundations of language. New York: Wiley, 1967.

Liberman, A. The grammars of speech and language. Cognitive Psychology, 1970, 1, 301-323.

Liberman, A.; Cooper, F., Shankweiler, D., \& StuddertKennedy, M. Perception of the speech code. Psychological Review, 1967, 74, 431-461.

Liberman, A., Harris, K., Kinney, J., \& Lane, H. The discrimination of relative onset-time of the components of certain speech and nonspeech patterns. Journal of Experimental Psychology, 1961, 61, 379-388.

Lieberman, P. On the evolution of language: A unified view. Haskins Laboratories Status Report of Speech Research, 1973, SR-33, 229-268.
Lieberman, P., Crelin, E., \& Klatt, D. Phonetic ability and related anatomy of the newborn, adult human, Neanderthal man and the chimpanzee. American Anthropologist, 1972, 74, 287-307.

Lieberman, P., Klatt, D., \& Wilson, W. Vocal tract limitations on the vowel repertoires of rhesus monkey and other nonhuman primates. Science, 1969, 164, 1185-1187.

Mattingly, I. Speech cues and sign stimuli. American Scientist, $1972,60,327-337$.

Mattingly, I., Liberman, A., Syrdal, A., \& Halwes, T. Discrimination in speech and nonspeech modes. Cognitive Psychology, 1971, 2, 131-157.

MORSE, P. Speech discrimination in six-week-old infants. Paper presented at the meetings of the Society for Research in Child Development, Minneapolis, Minnesota, April 1971.

Morse, $P$. The discrimination of speech and nonspeech stimuli in early infancy. Journal of Experimental Child Psychology, 1972. 14, 477-492.

Pisoni, D. On the nature of categorical perception of speech sounds. Unpublished doctoral dissertation, University of Michigan, 1971.

Pisoni, D. Auditory and phonetic memory codes in the discrimination of consonants and vowels. Perception \& Psychophysics, 1973, 13, 253-260.

PORT, D., \& Preston, M. Early apical stop production: A voice onset time analysis. Haskins Laboratories Status Report on Speech Research, 1972, SR-28/30, 125-149.

PORTER, R. Effects of delayed channel on the perception of dichotically presented speech and nonspeech sounds. Unpublished doctoral dissertation, University of Connecticut, 1971.

Rowell, T., \& Hinde, R. Vocal communication by the rhesus monkey (Macaca mulatta). Proceedings of the Zoological Society, London, 1962, 138, 279-294.

Sinnot, J. M. A comparison of speech sound discrimination in humans and monkeys. Unpublished doctoral dissertation, University of Michigan, 1974.

SteVens, K. Potential role of property detectors in the perception of consonants. M.I.T. Research Laboratory of Electronics Quarterly Progress Report, 1973, 110, 155-168.

Studdert-Kennedy, M., Liberman, A., Harris, K., \& Cooper, F. Motor theory of speech perception: A reply to Lane's critical review. Psychological Review, 1970, 77, 234-249.

Studdert-Kennedy, M., \& Shankweiler, D. Hemispheric specialization for speech perception. Joumal of the Acoustical Society of America, 1970, 48, 579-594.

Weisbard, C., \& Graham, F. Heart-rate change as a component of the orienting response in monkeys. Journal of Comparative and Physiological Psychology, 1971, 76, 74-83.

Williams, J. Novelty, GSR, and stimulus generalization. Canadian Journal of Psychology, 1963, 17, 52-61.

(Received for publication January 18, 1974; revision accepted July 27,1974 .) 